\title{
THE
}

\section{Duration of Exposure to Suboptimal Atmospheric Moisture Affects Nymphal Blacklegged Tick Survival}

\author{
Sarah E. Rodgers \\ Christine P. Zolnik \\ University of Rhode Island \\ Thomas N. Mather \\ University of Rhode Island, tmather@uri.edu
}

Follow this and additional works at: https://digitalcommons.uri.edu/pls_facpubs

Creative Commons License

cc) (i) (9)

This work is licensed under a Creative Commons Attribution-Noncommercial 3.0 License

\section{Citation/Publisher Attribution}

Rodgers, S. E., Zolnik, C. P., \& Mather, T. N. (2007). Duration of Exposure to Suboptimal Atmospheric Moisture Affects Nymphal Blacklegged Tick Survival. Journal of Medical Entomology, 44(2), 372-375. doi: 10.1093/jmedent/44.2.372

Available at: https://doi.org/10.1093/jmedent/44.2.372

This Article is brought to you for free and open access by the Plant Sciences and Entomology at DigitalCommons@URI. It has been accepted for inclusion in Plant Sciences and Entomology Faculty Publications by an authorized administrator of DigitalCommons@URI. For more information, please contact digitalcommonsgroup@uri.edu. 


\title{
Duration of Exposure to Suboptimal Atmospheric Moisture Affects Nymphal Blacklegged Tick Survival
}

\author{
SARAH E. RODGERS, ${ }^{1}$ CHRISTINE P. ZOLNIK, AND THOMAS N. MATHER \\ Center for Vector-Borne Disease, University of Rhode Island, Kingston, RI 02881
}

J. Med. Entomol. 44(2): 372-375 (2007)

\begin{abstract}
The biological processes affecting Ixodes scapularis Say survival are complex. Understanding these processes will be beneficial for predicting tick distribution and population dynamics. This research shows that the duration for which nymphal ticks are exposed to drying air is an important factor for their survival. Experimental analysis of variance results show that duration of exposure to dry air (duration) is as important as vapor pressure deficit (relative humidity) (duration, relative humidity, $P<0.0001$ ). Ticks do not survive when exposed to dry air for long periods; however, the return of humid air within $4-8 \mathrm{~h}$ has as large a positive impact on tick survival, as does constant humid air. This experiment exposes nymphal ticks to conditions of suboptimal humidity for different durations and then returns them to saturated conditions that are more typical of daily relative humidity fluctuations experienced during summer in southern New England forests.
\end{abstract}

KEY WORDS tick abundance, relative humidity, exposure duration, survival model

Blacklegged ticks, Ixodes scapularis Say, become infected with and transmit a myriad of disease agents causing emerging infections in the northeastern and midwestern United States. These agents include the Lyme disease bacterium, Borrelia burgdorferi, as well as the agents causing human babesiosis and granulocytic anaplasmosis (Childs et al. 1998). Despite some progress in understanding the dynamics of ticks in the northeastern United States, both at a variety of scales within the landscape and through time (Dister et al. 1997, Brownstein et al. 2003, Bunnell et al. 2003, Pardanani and Mather 2004, Rodgers and Mather 2006), the incidence of human Lyme disease and other tick-transmitted diseases continues to rise. Knowledge of the fundamental process of tick desiccation or moisture uptake will increase our understanding of processes affecting spatial distribution patterns and seasonal population dynamics of $I$. scapularis. Moreover, identifying processes underlying tick distribution patterns will be necessary to create predictive maps of tick abundance and disease risk (Hay et al. 2000).

Attaining useful information for predictive models of tick distribution has prompted several experiments and analyses. We investigated tick abundance in relation to soil moisture at 60 individual collection sites throughout Rhode Island (Rodgers et al. 2005, Rodgers and Mather 2006). Results suggested that the decline in tick populations due to time postemergence is more responsible for reducing tick abundance than drought-induced conditions (Rodgers et al. 2005, Zolnik 2005). However, over large areas tick abundance is, to some extent, related to a wetness index

\footnotetext{
${ }^{1}$ Corresponding author, e-mail: s.e.rodgers@swansea.ac.uk.
}

(Rodgers and Mather 2006). The wetness index created from Landsat Thematic Mapper remotely sensed imagery compared the visible and near infrared spectral bands. Longer infrared bands are most sensitive to both soil and plant moisture (Crist and Kauth 1986). In general, tick abundance in Rhode Island decreases with increasing distance from the coast, in a southnorth direction, just as does the wetness index. One factor related to the wetness index and dependent upon coastal proximity is relative humidity $(\mathrm{RH})$.

Combinations of environmental factors will be necessary to predict tick distributions, and host factors also may be involved (Ostfeld et al. 2006). However, we contend that weather variables affect the moisture budget within tick microhabitats and are therefore important determinants of vector activity and survival rates within a season. This relationship is true for the European tick Ixodes ricinus (L.), whose abiotic prerequisite for population survival is high humidity (more than $\approx 85 \mathrm{RH} \%$ ) in microhabitats at ground level (Daniel et al. 1998). Questing height of adult $I$. scapularis has been shown to be affected by humidity and mean distance moved was affected by temperature (Vail and Smith 2002). A laboratory experiment that held nymphal ticks at constant humidity demonstrated that survival of I. scapularis was not significantly different at $93 \%$ humidity compared with $100 \%$ humidity. It was only at a constant RH of $85 \%$ that survival rate decreased at a significantly faster rate (Stafford 1994). Nymphal tick populations decline due to host finding or death during summer; however, studies have shown that extreme drought conditions are responsible for reducing larval tick populations in 


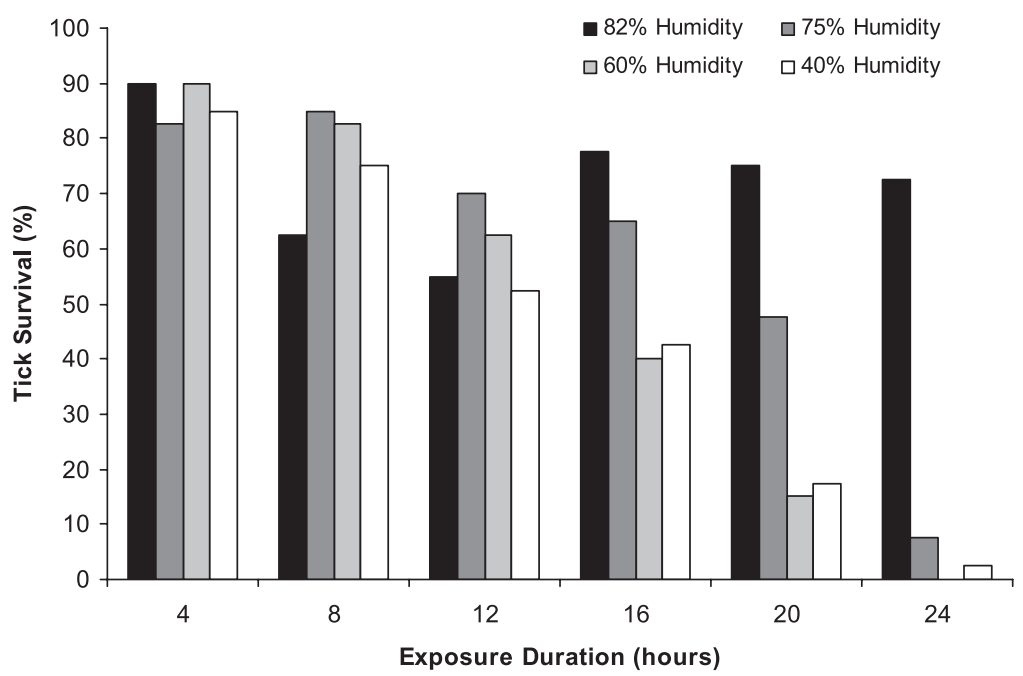

Fig. 1. Percentage of tick survival per humidity and exposure duration.

the midwestern United States (Jones and Kitron 2000). Nymphal ticks deprived of moisture desiccate within $48 \mathrm{~h}$, even though they are able to take up moisture from partially saturated air (Needham and Teel 1986, Stafford 1994).

In Rhode Island, a diurnal relative humidity range of $\approx 60 \%$ is common; from $100 \%$ in the morning to $40 \%$ in the hottest part of the afternoon (National Weather Station data, National Oceanic and Atmospheric Administration). An experiment designed to change both exposure duration and relative humidity would be more representative of natural conditions than experiments offering different continuous humidity exposures alone. There may exist an environmental moisture threshold that prevents or slows extraction of atmospheric moisture for nymphal I. scapularis. Moreover, there may be a duration of time for which this level must be sustained to cause ticks to stop questing and subsequently die. Increased understanding of this process might lead to development of more accurate predictive models of near-real time tick activity. Accordingly, we tested the ability of ticks to survive after daily exposure to dry air for different durations.

\section{Materials and Methods}

Field-collected female I. scapularis were blood fed, and replete ticks were held at $23^{\circ} \mathrm{C}$ at $>95 \%$ humidity in a photoperiod of 14:10 (L:D) h. After oviposition and larval hatching, first generation larvae were blood fed before fully engorged larvae were collected and held in vials under the same conditions until molting to nymphs. At 2 mo postemergence, the nymphal ticks were exposed to different relative humidity settings: $40,60,75$, and $82 \%$ over the course of $96 \mathrm{~h}$. Vials of 20 nymphal ticks each were exposed repeatedly to one humidity level for exposure durations of either; $4,8,12$, 16,20 , or $24 \mathrm{~h}$. Ticks were placed at a near-saturated humidity of $97 \%$ for the remainder of the 24 -h period. This near-saturation humidity was deemed sufficient as an experimental control according to results from a previous laboratory experiment (Stafford 1994). Each small humidity-conditioned chamber achieved its humidity level with saturated salts and was kept at a constant temperature $\left(23^{\circ} \mathrm{C}\right)$ in a large incubator. The saturated salts used to achieve different relative humidity levels: $\mathrm{MgCl}_{2}, 40 \% \mathrm{RH} ; \mathrm{Ca}\left(\mathrm{NO}_{3}\right)_{2} \cdot 4 \mathrm{H}_{2} \mathrm{O}, 60 \% \mathrm{RH} ; \mathrm{NaCl}$, $75 \% \mathrm{RH}$; and $\left(\mathrm{NH}_{4}\right)_{2} \mathrm{SO}_{4}, 82 \% \mathrm{RH}$ (Winston and Bates 1960). Humidity levels were verified using HOBO relative humidity sensors (HOBO, Onset, MA).

Tick vials were exchanged quickly between chambers on the appointed hour. After exposure to drier humidity, nymphal ticks were returned to the $97 \%$ humidity chamber to rehydrate. The 24 -h exposure vials were simply kept at one of the four constantly drier humidity levels. Two vials were used for each treatment of the six durations and four humidity levels to ensure that the experiment had replicates. Two extra vials were held under continuously moist conditions (97\% humidity). The entire experiment was repeated twice requiring a total of 2,000 ticks for both experimental rounds. Ticks were removed from vials for counting by temporarily removing the mesh cover (100 threads per inch). Counts of surviving ticks were converted to a percentage survival, and experimental rounds 1 and 2 were averaged before tick survival was modeled in SAS (SAS Institute, Cary, NC). An analysis of variance (ANOVA) was explored to investigate the main and interaction effects of humidity and duration on tick survival, including posthoc comparisons using the Tukey test and partial $\eta$-squared to show effect size.

\section{Results}

The survival rate of nymphal blacklegged ticks decreased after exposure to drier air for longer durations (Fig. 1). At the end of the experiment (96 h), the majority of ticks were desiccated at combinations of long exposure duration (e.g., 12, 20, and $24 \mathrm{~h}$ ) and dry humidity (e.g., 40 and $60 \%$ humidity levels). Tick sur- 


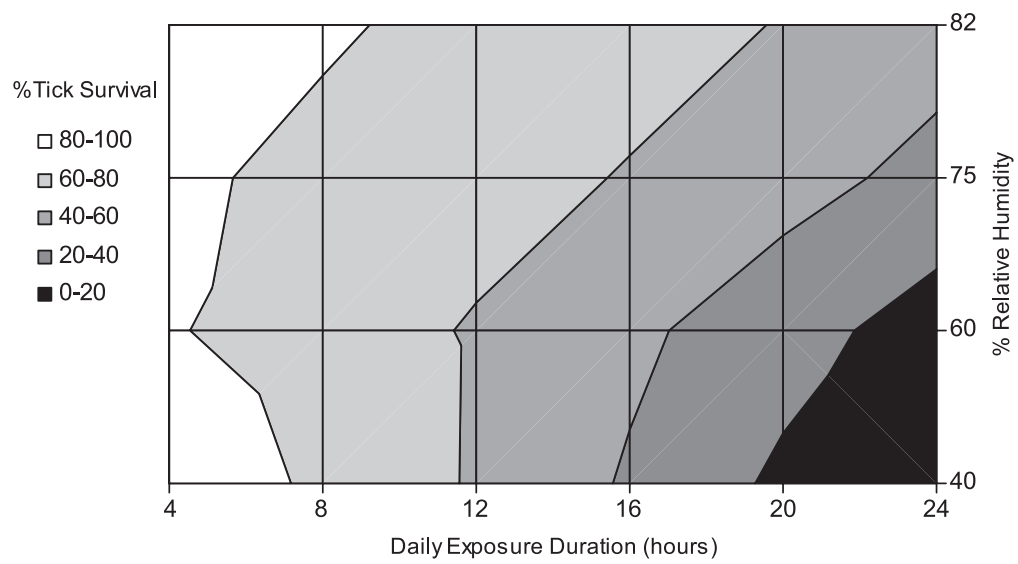

Fig. 2. Tick Survival model based on exposure duration to different humidity levels (note nonlinear scale on y-axis).

vival data were fitted with a quadratic model (Fig. 2), which depicts the relationship between tick survival (0-100\%), humidity level $(40,60,75$, and $82 \%)$, and exposure duration $(4,8,12,20$, and $24 \mathrm{~h})$. The traditional position of time on the $\mathrm{x}$-axis was replaced with exposure duration. Each class represents the proportion of ticks surviving when held under the different conditions. Most ticks ( $\geq 80 \%$ ) exposed to dry humidity conditions for short time durations survived (Fig. 2 , white area). In contrast, no ticks survived long durations of exposure to dry humidity (Fig. 2, dark gray). The modelled data show that as many as $60 \%$ of the ticks survived at $82 \%$ humidity, even if their exposure duration to this partially saturated air was constant. Model-derived estimates of tick survival were compared with experimentally observed values; the model had a good prediction rate with an $R^{2}$ value of 0.73 , significant at $P<0.005$.

ANOVA showed that the main effects for duration and humidity and the interaction effects of humidity and duration on tick survival were significant (Table 1). We reduced the significance level to 0.01 to compensate for lack of homogenous variance across groups. Posthoc comparisons using the Tukey test indicated that the mean score for the $40 \% \mathrm{RH}$ was significantly different from 60 to $82 \%$ RH levels. Exposure duration posthoc tests also revealed several significant differences; tick survival after 4-h exposure to a range of $\mathrm{RH}$ levels was significantly different from all other exposure durations; 8-h exposure was significantly different from 20- and 24-h exposures; 12-h exposure was different from the 24 -h exposure. Partial $\eta$-squared results showed that duration had the largest effect on tick survival, although both variables and the

Table 1. ANOVA results of exposure duration (duration), relative humidity (RH), and interaction effects on tick survival

\begin{tabular}{lcc}
\hline \hline & $P$ value & Partial $\eta^{2}$ \\
\hline Exposure duration & $<0.0001$ & 0.825 \\
RH & 0.0001 & 0.686 \\
RH $\times$ duration & 0.0039 & 0.666 \\
\hline
\end{tabular}

interaction component showed moderate-to-large effects (Cohen 1988) (Table 1).

\section{Discussion}

The statistically significant relationship between relative humidity, exposure duration, and nymphal $I$. scapularis survival, increases our knowledge of the ability of this tick to withstand desiccation.

Previous studies found reduced survival rates of nymphs constantly exposed to relative humidity $<85 \%$ at $27^{\circ} \mathrm{C}$ (Stafford 1994). However, in this study, nymphs readily survived exposures to dry conditions $(<82 \%)$ as long as they were returned to saturated air daily. It seems likely that typical summer humidity conditions in forested sites of southern coastal New England (range $40-100 \% \mathrm{RH}$ ) would be permissive for extended tick longevity even when there has been no rainfall for many days. The good fit of the model to the raw data will be useful in developing predictive models of tick activity and abundance.

Ticks survive brief periods $(0-4 \mathrm{~h})$ of dry air; however, survival is significantly reduced when exposed to extended periods of dry air. We observed a continuous linear decrease in tick survival with increasing exposure duration ( $>4$-h exposure). Similarly, a linear decrease in survival seems to occur with decreasing $\mathrm{RH}$ of 75,60 , and $40 \% \mathrm{RH}$, respectively. Interestingly, we observed a large difference in tick survival rates between 82 and $75 \%$ RH. For example, only eight ticks survived at constant exposure to $75 \% \mathrm{RH}$, whereas 73 ticks survived at $82 \% \mathrm{RH}$. This suggests the possibility of a threshold, between 75 and $82 \%$, below which the vapor pressure deficit is too large for these ticks to easily extract moisture from the air, although individual ticks may have a greater ability than others to extract moisture and extend their survival.

The artificial construct of this laboratory experiment meant that ticks were exposed to dry air and then immediately returned to near-saturated air. In Rhode Island, it is possible that on occasion an air mass with dramatically different relative humidity might arrive; 
however, typically there will not be such abrupt changes. Instead, RH will gradually increase as temperatures fall during the night. At cooler temperatures the capacity of air to hold water vapor is reduced; therefore, it will be easier for ticks to extract water vapor from cooler air with an increased $\mathrm{RH}$ rather than from warmer air at a lower $\mathrm{RH}$. It is likely that ticks will be more active at dawn because of the moist conditions at this time. This may mean that ticks are questing while the nocturnal whitefooted mouse, Peromyscus leucopus, is active and before many people are present, somewhat limiting human tick bite risk after dry weather. Large differences in questing patterns of different ticks have been established, suggesting that each species and life stage has its own environmental criteria (Schulze and Jordan 2003). Incorporating exposure to different humidity levels, as in this experiment, moves a step toward eventually modeling these often gradual humidity changes occurring daily. Moreover, this experiment has further increased our understanding of an important process of tick survival, thereby helping explain their daily, and potentially, their seasonal dynamics and spatial distribution. The risk of tick-transmitted diseases such as Lyme disease, babesiosis, and anaplasmosis can be assessed from tick distributions (Mather et al. 1996, Stafford et al. 1998).

The next step in this work could be to use this laboratory model to help design a field-based experiment to validate laboratory results and further elucidate daily host-seeking activity, or lack thereof, as a response to unfavorable relative humidity conditions. It is our hypothesis that tick mortality will be most influenced by their immediate litter layer microhabitat. However, relating microhabitat humidity measurements to those data detectable by remote sensing instruments will be a necessary challenge to achieve a dense spatial network of humidity data, and hence, potential weekly tick population predictions. Moreover, using validation data from adjacent areas, tick abundance may be estimated for regional scales by using climate databases, geographic information systems, and remote sensing tools.

\section{Acknowledgments}

This research was supported by USDA special grant OJ 2005-06174, Hatch project R00037, and a gift from the Island Fund of the New York Community Trusts. This article is contribution 5064 of the Rhode Island Agricultural Experiment Station.

\section{References Cited}

Brownstein, J. S., T. R. Holford, and D. Fish. 2003. A climate-based model predicts the spatial distribution of the Lyme disease vector Ixodes scapularis in the United States. Environ. Health Perspect. 111: 1152-1157.

Bunnell, J. E., S. D. Price, A. Das, T. Shields, and G. E. Glass. 2003. Geographic information system and spatial analysis of adult Ixodes scapularis nymphs in the Middle Atlantic region of the U.S.A. J. Med. Entomol. 40: 570-576.
Childs, J., R. E. Shope, D. Fish, F. X. Meslin, C. J. Peters, K. Johnson, E. Debess, D. Dennis, and S. Jenkins. 1998. Emerging zoonoses. Emerg. Infect. Dis. 4: 453-454.

Cohen, J. 1988. Statistical power analysis for the behavioral sciences. Academic, New York.

Crist, E. P., and R. J. Kauth. 1986. The tasseled cap demystified. Photogrammetric Eng. Remote Sens. 52: 81-86.

Daniel, M., J. Kolar, P. Zenam, K. Pavelka, and J. Sadlo. 1998. Predictive map of Ixodes ricinus high-incidence habitats and a tick-borne encephalitis risk assessment using satellite data. Exp. Appl. Acarol. 22: 417-433.

Dister, S. W., D. Fish, S. M. Bros, D. H. Frank, and B. L. Wood. 1997. Landscape characterization of periodomestic risk for Lyme disease using satellite imagery. Am. J. Trop. Med. Hyg. 57: 687-692.

Hay, S. I., S. E. Randolph, and D. J. Rogers. 2000. Remote sensing and geographical information systems in epidemiology. Academic, San Diego, CA.

Jones, C. J., and U. D. Kitron. 2000. Populations of Ixodes scapularis (Acari: Ixodidae) are modulated by drought at a Lyme disease focus in Illinois. J. Med. Entomol. 37: $408-415$.

Mather, T. N., M. C. Nicholson, R. Hu, and N. J. Miller. 1996. Entomological correlates of Babesia microti prevalence in an area where Ixodes scapularis (Acari: Ixodidae) is endemic. J. Med. Entomol. 33: 866-870.

Needham, G. R., and P. D. Teel. 1986. Water balance by ticks between bloodmeals. In H. J. Sauer, Jr. [ed.], Morphology, physiology and behavioural biology of ticks. Ellis Horwood Ltd., Chichester, United Kingdom.

Ostfeld, R. S., C. D. Canham, K. Oggenfuss, R. J. Winchcombe, and F. Keesing. 2006. Climate, deer, rodents, and acorns as determinants of variation in Lyme-disease risk. PLoS Biol. 4: 1058-1068.

Pardanani, P., and T. N. Mather. 2004. Lack of spatial autocorrelation in fine-scale distributions of Ixodes scapularis (Acari: Ixodidae). J. Med. Entomol. 41: 861-864.

Rodgers, S. E., and T. N. Mather. 2006. Evaluating satellite sensor derived indices for Lyme disease risk prediction. J. Med. Entomol. 43: 337-343.

Rodgers, S. E., C. P. Zolnik, and T. N. Mather. 2005. Applications of a climatic water budget to tick-borne disease research. Phys. Geogr. 26: 480-488.

Schulze, T. L., and R. A. Jordan. 2003. Meteorologically mediated diurnal questing of Ixodes scapularis and Amblyomma americanum (Acari: Ixodidae) nymphs. J. Med. Entomol. 40: 395-402.

Stafford, K. C. 1994. Survival of immature Ixodes scapularis (Acari: Ixodidae) at different relative humidities. J. Med. Entomol. 31: 310-314.

Stafford, K. C., M. L. Cartter, L. A. Magnarelli, S.-H. Ertel, and P. A. Mshar. 1998. Temporal correlations between tick abundance and prevalence of Lyme disease. J. Clin. Microbiol. 36: 1240-1244.

Vail, S. G., and G. Smith. 2002. Vertical movement and posture of blacklegged tick (Acari: Ixodidae) nymphs as a function of temperature and relative humidity in laboratory experiments. J. Med. Entomol. 39: 842-846.

Winston, P. W., and D. H. Bates. 1960. Saturated solutions for the control of humidity in biological research. Ecology 41: 232-237.

Zolnik, C. P. 2005. Effect of soil moisture on host-seeking activity of nymphal Ixodes scapularis pp. 78. M.S. thesis, University of Rhode Island, Kingston, RI.

Received 15 August 2006; accepted 18 November 2006. 